\title{
The use of local concentrated heat versus topical acyclovir for a herpes labialis outbreak: results of a pilot study under real life conditions
}

This article was published in the following Dove Press journal:

Clinical, Cosmetic and Investigational Dermatology

4 November 2013

Number of times this article has been viewed

\author{
Johannes Wohlrab' \\ Franziska Voß ${ }^{2}$ \\ Christian Müller ${ }^{2}$ \\ Lars C Brenn ${ }^{2}$ \\ 'Department of Dermatology \\ and Venereology, Martin Luther \\ University of Halle-Wittenberg, Halle, \\ ${ }^{2}$ Department of Medical Science and \\ Operations, Riemser Pharma GmbH, \\ Greifswald, Germany
}

Background: Frequent outbreak of herpes labialis can affect quality of life by prodromes like burning, itching, and swelling. Topical applied preparations aim to shorten the duration of symptoms, inhibit the virus replication and/or accelerate the healing process. Local concentrated heat $(\mathrm{LCH})$ can reduce burning, itching, or swelling of the skin by influence of mechano-heat sensitive afferent neurons.

Patients and methods: To examine the effectiveness of two different topical applications (LCH versus topical acyclovir [TACV]) under real life conditions, we conducted a prospective, observational, reference-controlled cohort pilot study with 103 patients. Occurrence of prodromal burning, itching, swelling, and quality of life were assessed.

Results: The LCH observation group (OG) showed a significantly faster improvement in all symptoms after 1-day of application than the TACV OG. The burden and duration of disease was lower and shorter in the LCH OG than in the TACV OG.

Conclusions: The prodromal symptoms in recurrent herpes labialis were attenuated more effectively by LCH than by TACV.

Keywords: herpes labialis, local concentrated heat, acyclovir

\section{Introduction}

Herpes labialis or cold sores are primarily caused by infections of herpes simplex virus type 1 (HSV-1), which has a seroprevalence of $>90 \%$ within the adult population in Europe. ${ }^{1} \mathrm{HSV}-1$ is a member of the virus subfamily of $\alpha$-Herpesviridae. The virions consist of nucleocapsid, tegument, and a lipid envelope originated from the host cell with embedded virus encoded glycoproteins at the surface. ${ }^{2}$ In addition to a total of 30 viral proteins the virions contain also cellular proteins (eg, heat shock protein [HSP] and actin). The viral replication cycle has several phases. After the virions are absorbed in the target cell they bind to structures of the cellular surface (eg, carbohydrate polymers and protein receptors) via glycoproteins and the envelope merges with the cell membrane. ${ }^{3}$ After the liberation of the nucleocapsid into the cytoplasm and its migration to the nuclear pores via microtubules, the viral genomic deoxyribonucleic acid (DNA) infiltrates the nucleus and circulates. Through cascading expression of different gene groups the virus genome finally replicates together with other virus components into cell vesicles. ${ }^{4}$ Merging with the cell membrane the fully developed virus particle is released. Aberrant, non-infectious virus particles are distinguished from fully developed, infectious virions. ${ }^{5}$ Virions have the ability to remain in a state of latency in specific target cells. Different internal (eg, stress and immunosuppression) or external (eg, ultraviolet [UV] light and hormones) factors can trigger the reactivation
Correspondence: Johannes Wohlrab Department of Dermatology and Venereology, Martin Luther University of Halle-Wittenberg, Ernst-GrubeStraße 40, D-06097 Halle, Germany Tel +49345 5573933

Fax +49345 5573944

Email johannes.wohlrab@medizin.unihalle.de 
of the latent virus genome and thus the development of infectious virions. ${ }^{1,2}$ After primary infection with HSV-1 (gingivostomatitis herpetica), which often shows no or only mild symptoms, a latency phase with no symptoms follows that can vary in duration. The abovementioned trigger factors can cause recurrent reactivation. ${ }^{2,6-8}$ Frequency and severity of the clinical symptoms vary individually. Reactivation is characterized by a typical succession of painful burning, erythema, and blistering. ${ }^{9}$ A commonly used therapeutic intervention is the topic application of acyclovir starting in the prodromal phase. ${ }^{10}$ Acyclovir as an antimetabolite inhibits the replication of HSV mainly by blocking the viral thymidine kinase. ${ }^{11}$ Since acyclovir reaches relevant bioavailability only within the skin through epicutaneous application, it has no direct influence on neurogenic prodromal symptoms such as pain, burning, and pruritus. ${ }^{12}$

\section{Materials and methods}

\section{Study design}

This non-interventional pilot study (NIS) was conducted between April and November 2012 in collaboration with eleven pharmacies in Germany. The study had been approved by the ethics committee of the University of Greifswald, registered at German authorities and at "German Register for Clinical Studies" (DRKS identifier: 00004777). The NIS was designed as a prospective, reference controlled, observational cohort study with 103 patients to describe the symptomatic outcomes after use of local concentrated heat $(\mathrm{LCH})$ or a topical acyclovir (TACV) treatment. For application of LCH, a CE-certified medical device of class $2 \mathrm{~A}$ (Herpotherm ${ }^{\circledR}$, Riemser Pharma $\mathrm{GmbH}$, Greifswald, Germany) with a guaranteed durationheat-constant was used, which is intended for non-invasive administration onto the skin. ${ }^{13}$ The $\mathrm{LCH}$ device produces a microchip controlled concentrated thermal impulse of $50^{\circ} \mathrm{C}-53^{\circ} \mathrm{C}$ on a $38.5 \mathrm{~mm}^{2}$ covered plate for 4 seconds. The NIS was patient-initiated, and involved the self-application under real life conditions.

Patients in need for treatment who bought either a TACV or a LCH device were asked by the pharmacist to participate in the study. The majority (63\%) of the patients had used TACV in the past, only $3 \%$ of the patients had been aware of LCH as an alternative therapy. After the pharmacist informed the patient about the aim of the study, the patient was asked to sign the informed consent form. There was no selection of subjects to one or another observation group (OG). TACV and $\mathrm{LCH}$ were applied according to the instructions in the summary of product characteristics (SPC). TACV: 5 times per day for 5 days; LCH maximum of 5 times per day until symptoms disappeared.

\section{Pharmacist's questionnaire}

Information regarding the demographics of the patients, visibility of vesicles, possible current and previous therapies, and the rate of recurrences per year were obtained for both OGs. Finally, each patient was explicitly informed about the "SPC/instruction for use" for their respective treatment option: when to start, how to proceed, and how to enter the data into the patient's questionnaire.

\section{Patient's questionnaire}

Herpes labialis is most often treated with over-the-counter (OTC) drugs. ${ }^{9}$ As the outbreaks are not predictable, patients personally decide when to start the treatment, based on typical first symptoms of a herpes labialis recurrence period, such as itching, prickling, or a feeling of tension at the lips. From the beginning of prodromal symptoms (burning, itching, and/or swelling of the lips) and during 7 days of treatment patients were asked to determine

Table I Patients and treatment characteristics during former recurrence episodes

\begin{tabular}{|c|c|c|c|c|}
\hline \multirow[t]{2}{*}{ Characteristics } & \multicolumn{2}{|c|}{$\begin{array}{l}\text { LCH } \\
(\mathrm{N}=5 \mathrm{I})\end{array}$} & \multicolumn{2}{|c|}{$\begin{array}{l}\text { TACV } \\
(\mathrm{N}=52)\end{array}$} \\
\hline & $\overline{\mathbf{N}}$ & $\%$ & $\mathbf{N}$ & $\%$ \\
\hline \multicolumn{5}{|l|}{ Sex } \\
\hline Male & 13 & 25.5 & 16 & 30.8 \\
\hline Female & 38 & 74.5 & 36 & 69.2 \\
\hline $\begin{array}{l}\text { Prodromes visible at the time } \\
\text { of recruitment }\end{array}$ & 23 & 45.1 & 31 & 59.6 \\
\hline \multicolumn{5}{|c|}{ Number of herpes labialis episodes per year } \\
\hline $\mathrm{I}-2$ & 10 & 19.6 & 17 & 32.7 \\
\hline $3-4$ & 17 & 33.3 & 21 & 41.2 \\
\hline $5-6$ & 17 & 33.3 & 9 & 17.3 \\
\hline$>6$ & 7 & 13.7 & 5 & 9.6 \\
\hline \multicolumn{5}{|l|}{ Former treatment modalities } \\
\hline Domestic remedies & 9 & 17.6 & 11 & 21.2 \\
\hline Topical Acyclovir & 36 & 70.6 & 42 & 80.8 \\
\hline Topical Penciclovir & 10 & 19.6 & 4 & 7.7 \\
\hline Local concentrated heat & 3 & 5.9 & I & 1.9 \\
\hline RX-drugs & 7 & 13.7 & 2 & 3.8 \\
\hline \multicolumn{5}{|c|}{ Average number of prodromes during former recurrences } \\
\hline I & 7 & 13.7 & II & 21.2 \\
\hline 2 & 14 & 27.5 & 19 & 36.5 \\
\hline 3 & 13 & 25.5 & 6 & 11.5 \\
\hline 4 & 10 & 19.6 & 9 & 17.3 \\
\hline$>4$ & 7 & 13.7 & 7 & 13.5 \\
\hline
\end{tabular}

Abbreviations: LCH, local concentrated heat; TACV, topical acyclovir; RX-drugs, prescription drugs; N, number. 
if any prodromes or crusts were present. To record the daily development of swelling, pruritus, and burning we used a patient diary with a Numeric Analog Scale (NAS; $0=$ no sensation; $9=$ worst sensation imaginable). Quality of Life (QoL) was also assessed daily using a NAS. To ensure therapy adherence with "SPC/instruction for use", patients were asked to enter the number of treatments per day. After 7 days of observation, patients were asked to evaluate the success as well as the tolerability of their chosen therapy using a 5 point Likert scale. All adverse events were reported.

\section{Incentives}

Patients could choose between vouchers for books, fuel, or pharmacy products as a thank you for their participation in the study. Patients received the voucher only when they brought back the completed patient's questionnaire to the pharmacy after the observation period of 7 days.

\section{Data management and statistical analyses}

All patients that provided data during the therapy period were included in statistical analyses. A database (Microsoft Excel for MAC V14.3.2, IBM Corporation, Armonk, NY, USA)
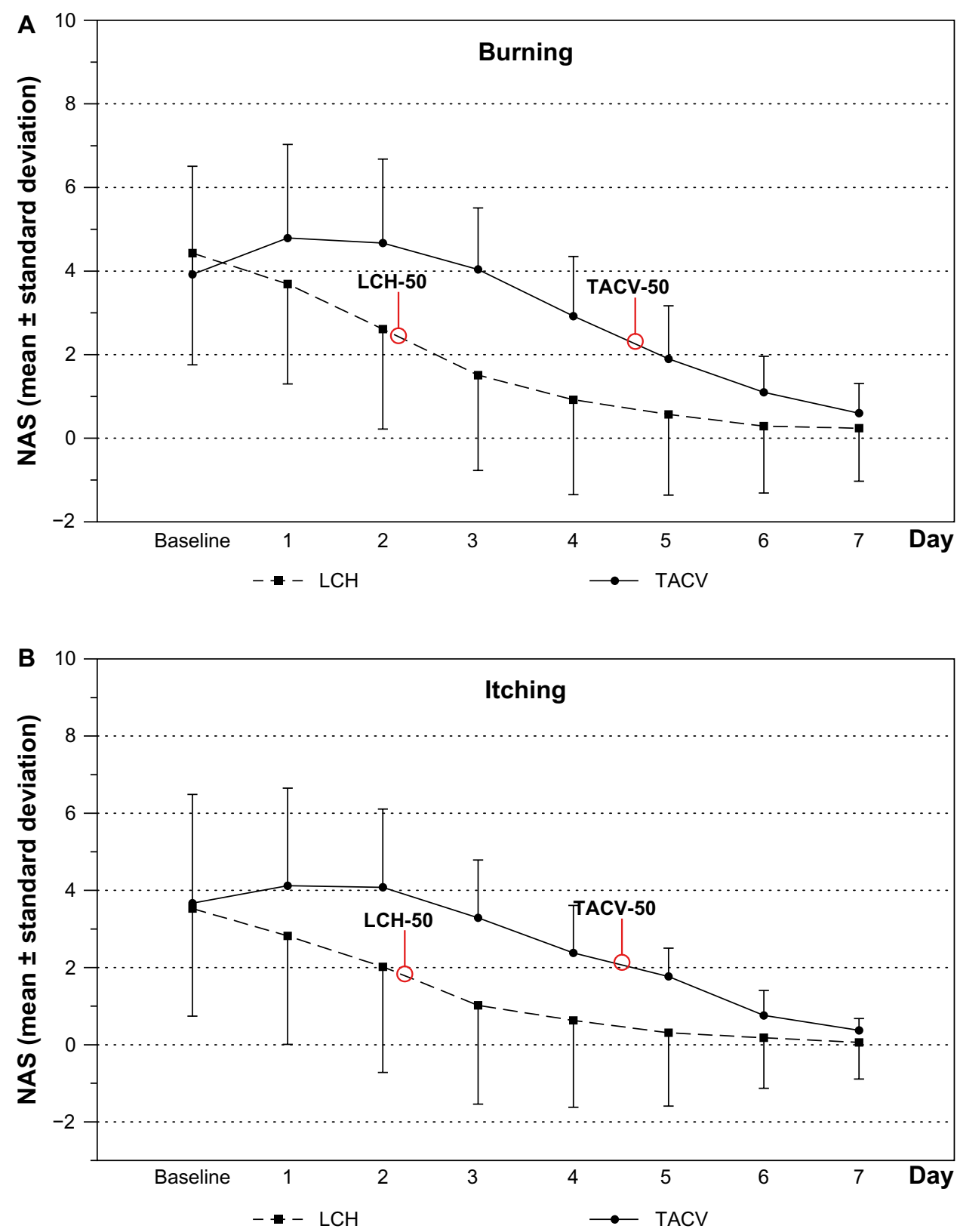

Figure I (Continued) 

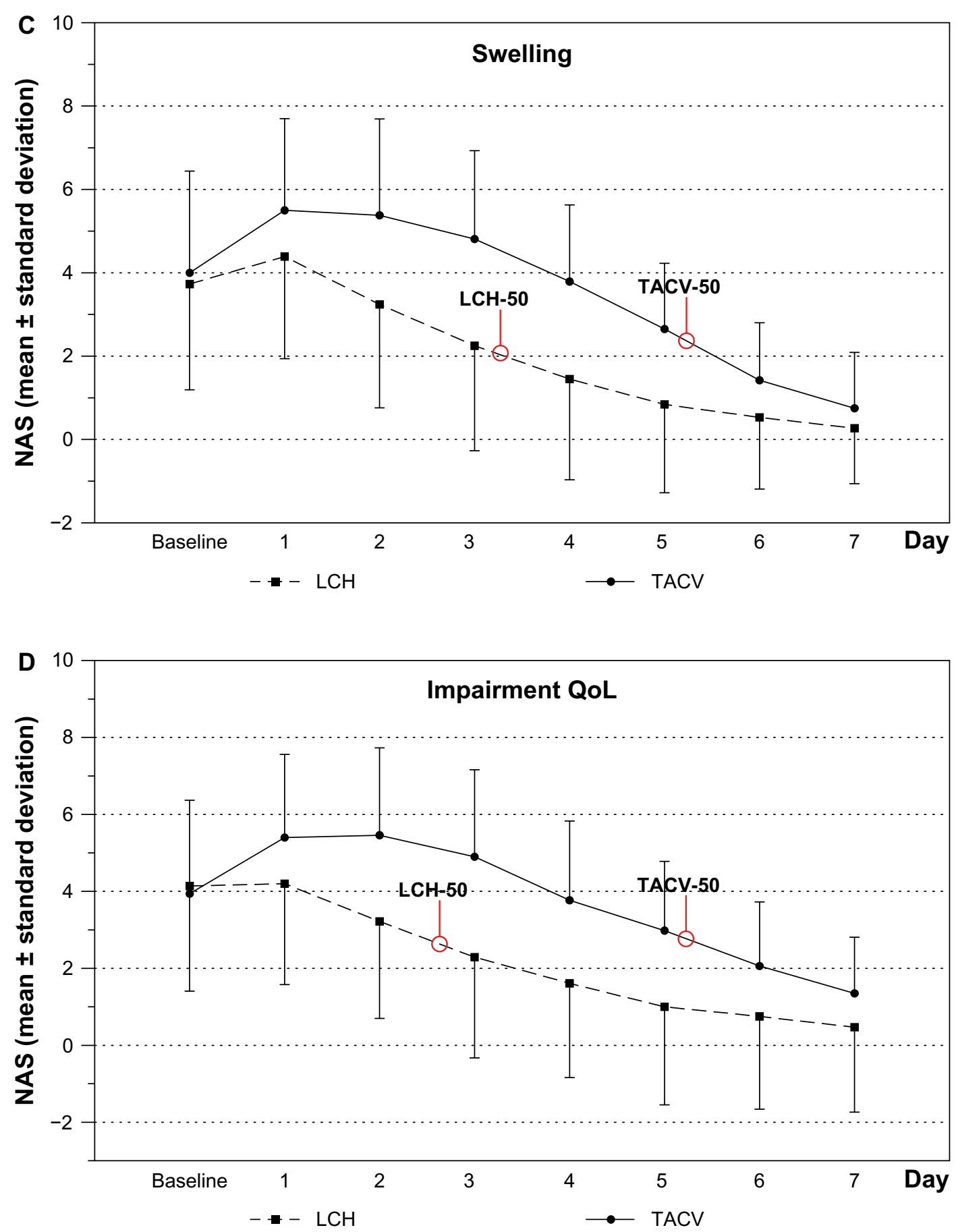

Figure I NAS progression as mean \pm standard deviation of $(\mathbf{A})$ burning, (B) itching, (C) swelling, and (D) QoL.

Notes: $\mathrm{LCH}: \mathrm{N}=51$; TACV: $\mathrm{N}=52 ; 0=$ no sensation; $9=$ worst sensation imaginable.

Abbreviations: LCH, local concentrated heat; NAS, numeric analog scale; QoL, quality of life; TACV, topical acyclovir.

was used for single data entry. The structure of the database was adapted to the questionnaire. Descriptive statistics were produced including frequencies (or percentages) for categorical variables, as well as means, standard deviations, medians, minimums, and maximums for continuous variables. Single descriptors and frequencies of various factors were tabulated. SAS ${ }^{\circledR}$ Version 9.2 (SAS Institute Inc., Cary, NC, USA) and Origin 6.1 G (Origin Lab Corporation, Northampton, MA, USA) were used to conduct all analyses. Associations between factors were determined using Fisher's exact tests, and the Wilcoxon-Mann-Whitney test was used to compare mean scores of patients' outcomes of the LCH with 


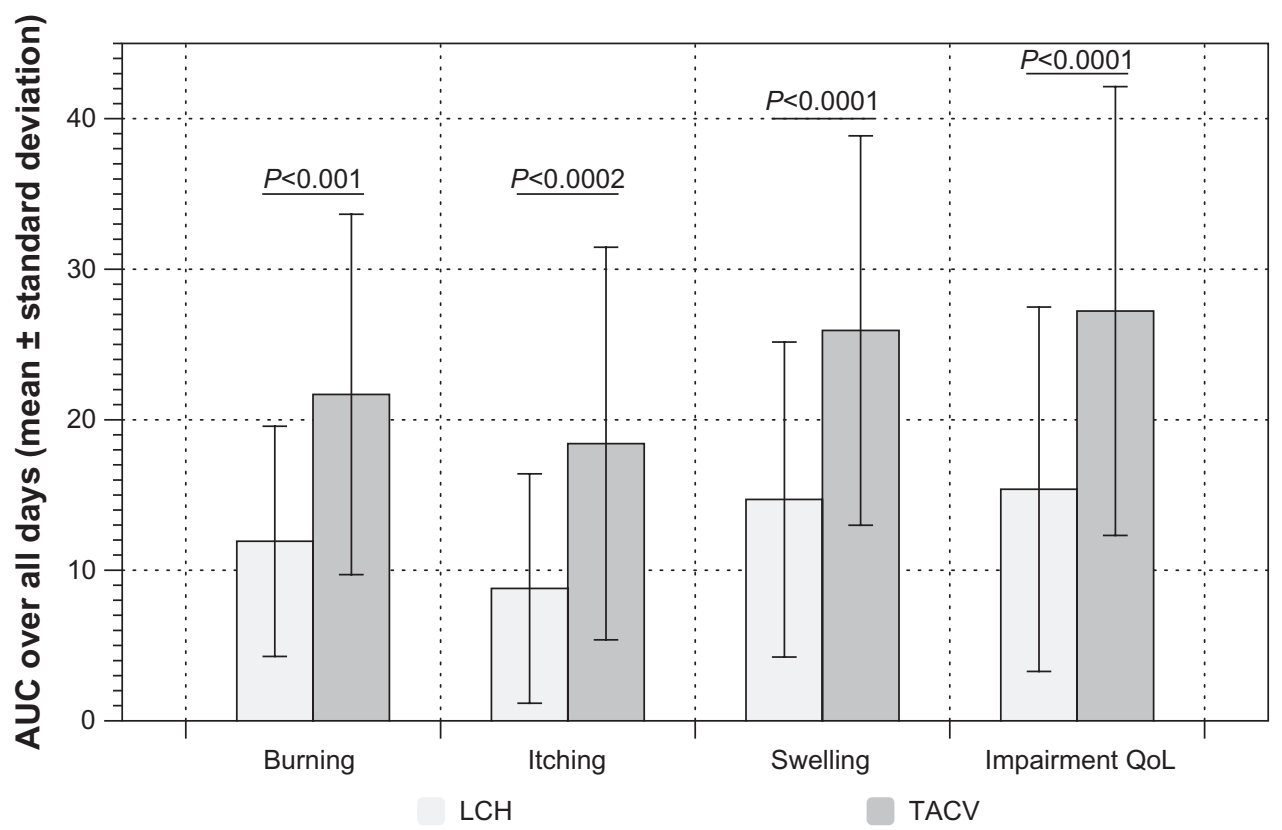

Figure 2 NAS progression as mean \pm standard deviation over all days of burning, itching, swelling, and QoL. Notes: $\mathrm{LCH}: \mathrm{N}=5$ I; TACV: $\mathrm{N}=52 ; 0=$ no sensation; $9=$ worst sensation imaginable.

Abbreviations: AUC, area under the curve; LCH, local concentrated heat; NAS, numeric analog scale; QoL, quality of life; TACV, topical acyclovir.

TACV therapies. The statistical tests was 2-tailed and a probability of $P<0.05$ was considered statistically significant.

\section{Results}

\section{Characteristics of the study population}

A total of 103 patients were enrolled in this study. Fifty-one patients were exposed to LCH while fifty-two were treated with TACV. The mean age of the patients was $40 \pm 15$ years (range 18-72 years). The LCH therapy OG consisted of 13 males and 38 females. Sixteen males and 36 females were treated with TACV. Overall, $72 \%$ of the patients were female. A total of 41 patients $(80 \%)$ treated with $\mathrm{LCH}$ and 35 patients $(67 \%)$ treated with TACV had more than two recurrences per year. Eighty-six percent of patients in the LCH OG (44 of 51) and 79\% of the TACV OG (41 of 52) developed two or more classical lesions during former recurrences. Fifty-four out of 103 patients developed lesions immediately before the start of treatment. Table 1 shows the sex, number of herpes labialis episodes per year, former treatment modalities, and the average number of prodromes during former recurrences.

\section{Burning, itching, swelling, and QoL}

Treatment via both TACV and LCH reduced burning, itching, swelling, and led to less deterioration in QoL over the observation period. There was a significantly faster improvement for these symptoms and QoL (assessed by NAS) of herpes labialis in the LCH OG than in the TACV OG (Figures 1A-D, 2, and Table 2). This was noticeable after one day of treatment (day 2; $P<0.05$ ). Patients in the LCH OG reported a spontaneous improvement in burning, itching, swelling, and QoL after 1-day of treatment. Patients in the TACV OG reported an improvement in all observed symptoms after 2 days. In general, the perception of burning, itching, and swelling corresponded with the QoL curve in both OGs. Mean NAS score of itching, swelling, burning, and impairment of QoL was reduced by $50 \%$ at least 2 days earlier in the LCH OG than in the TACV OG (Figure 1A-D).

Table 2

\begin{tabular}{lllllllll}
\hline Parameter & Baseline & Day I & Day 2 & Day 3 & Day 4 & Day5 & Day 6 & Day 7 \\
Burning & 0.210 & 0.046 & $<0.0001$ & $<0.001$ & $<0.001$ & 0.0003 & 0.005 & 0.133 \\
Itching & 0.943 & 0.044 & 0.0002 & $<0.0001$ & $<0.0001$ & $<0.0001$ & 0.016 & 0.056 \\
Swelling & 0.608 & 0.032 & $<0.0001$ & $<0.0001$ & $<0.0001$ & $<0.0001$ & 0.007 & 0.113 \\
QoL & 0.702 & 0.091 & 0.0225 & $<0.0001$ & $<0.0001$ & $<0.0001$ & $<0.000$ I & 0.004 \\
\hline
\end{tabular}

Abbreviation: QoL, quality of life. 


\section{Development of prodromes}

The burden and duration of all symptoms was lower and shorter in the LCH than in the TACV OG (Figure 3). The mean time for prodromes to be present was 2.3 days for the LCH OG and 4.5 days for patients treated with TACV.

\section{Assessment of success and tolerance}

Success in application was reported as "very good" by $53 \%$ of patients from the LCH OG but in only $12 \%$ of the TACV OG (Figure 4A). Self-reported success of the herpes labialis treatment by patients was associated with the type of application ( $P<0.0001$, Fisher's exact tests). Tolerance was comparable in both OGs (Figure 4B).

\section{Adverse events}

During this study, only one case in the LCH OG reported any skin irritation. No serious adverse events were reported.

\section{Discussion}

To date, there are no other studies that investigated the influence of topical herpes labialis treatment via patient reported outcomes under real life conditions. However, this study clearly has its limitations. To start with, it must be stated that at no time a clinical assessment of the condition took place, whether it was based on medical examination or on microbiological and/or infection-serological findings. Therefore, it cannot completely be ruled out that false diagnoses have been included in the study. Furthermore, no statement on potential therapy resistances can be made. Thus, the homogeneity of the study population cannot be assured. Additionally, it must be considered that the presentation of LCH (previously unknown to most of the patients) as a therapy option within the study setting, could have indirectly influenced the choice of therapy. However, equal prices eliminated the possibility of preferences due to pecuniary reasons.

The improvement of burning, itching, and swelling as a measure for QoL are key outcome parameters. ${ }^{14}$ Both OG in the present study found that treatment had a positive influence on QoL. The perception of burning, itching, and swelling correlated clearly with the QoL in both OGs. The use of LCH led to an immediate improvement of these prodromal symptoms. These effects have also been observed in another cohort study investigating the effect of $\mathrm{LCH}$ after insect stings. ${ }^{15}$

Application of $\mathrm{LCH}$ (approx. $53^{\circ} \mathrm{C}$ for 4 seconds) causes thermal conduction into the skin. ${ }^{16}$ This is determined mainly by the thermal diffusivity of skin, which is $0.40 \mathrm{~cm}^{2} / \mathrm{s} \times 10^{3} .{ }^{17}$ Other physical parameters, such as heat convection and heat radiation have only marginal significance and can be neglected according to current knowledge. It can be assumed that using the present setting of $\mathrm{LCH}$ the vital epidermis reaches a temperature of $47^{\circ} \mathrm{C}-48^{\circ} \mathrm{C}$ for a time period of approximately 2-3 seconds. This thermal effect is called "heating" and has a biological response of functional but fully reversible alterations. ${ }^{18,19}$ In deeper layers, a lower isotherm level can be assumed that leads to reactive hyperemia in the sense of a neurosensory initiated hyperperfusion. ${ }^{19-22}$

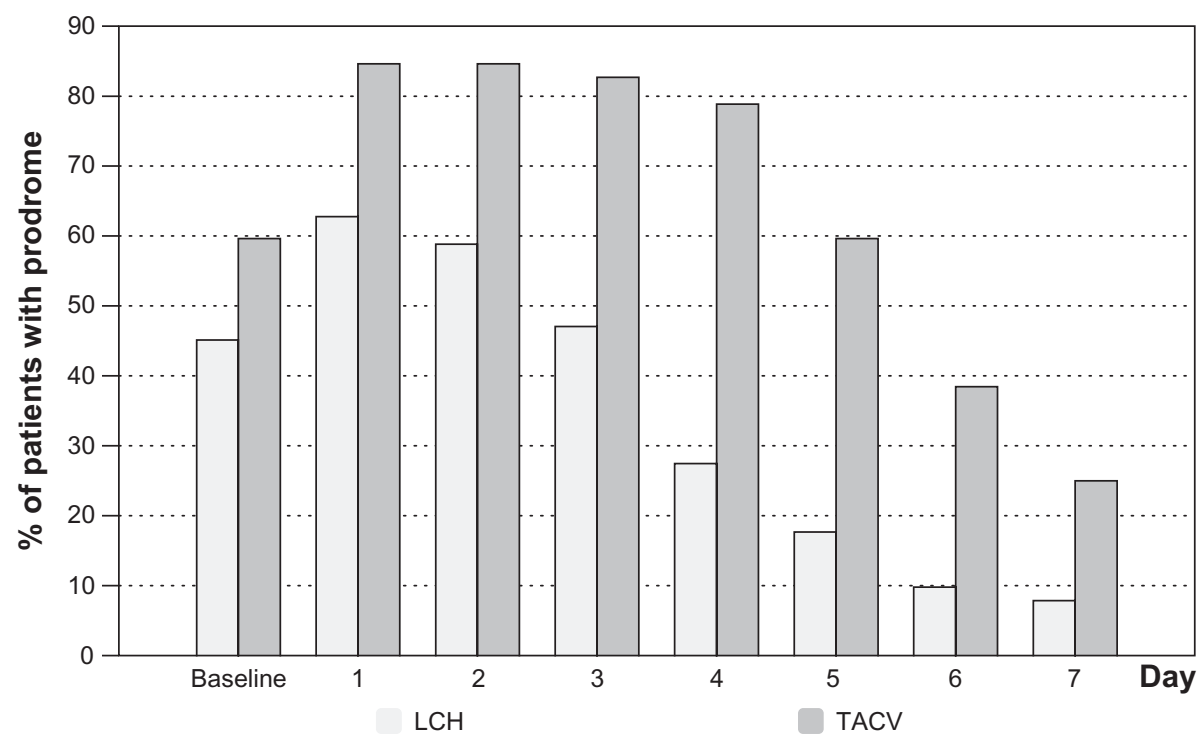

Figure 3 Distribution of patients with prodromes in both cohorts during the 7 day observation period. Notes: LCH: $\mathrm{N}=5 \mathrm{I}$; TACV: $\mathrm{N}=52$.

Abbreviations: $\mathrm{LCH}$, local concentrated heat; TACV, topical acyclovir. 

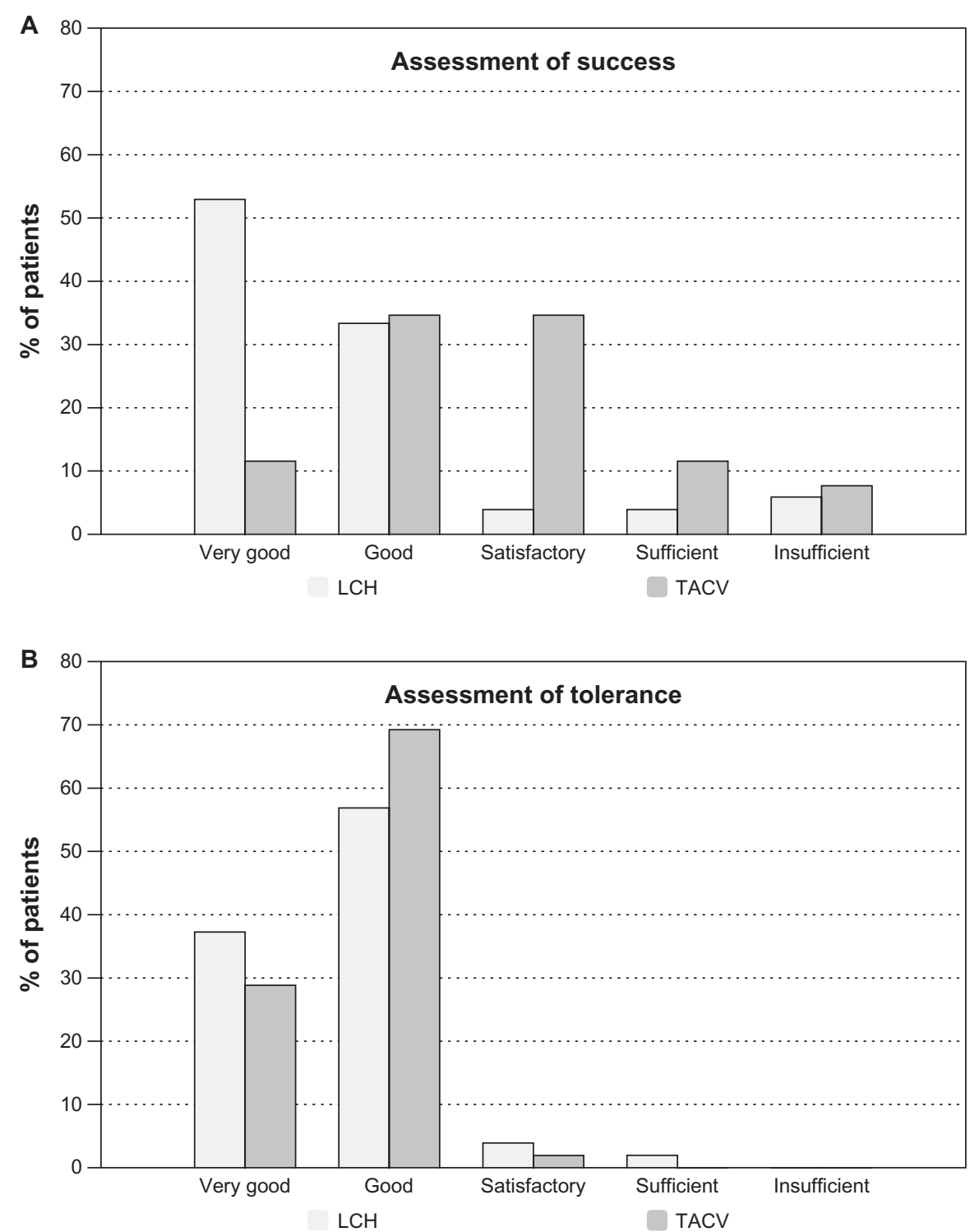

Figure 4 Patient reported (A) tolerance and (B) success of each cohort. Notes: LCH: $\mathrm{N}=5 \mathrm{I}$; TACV: $\mathrm{N}=52$.

Abbreviations: $\mathrm{LCH}$, local concentrated heat; TACV, topical acyclovir.

Efficacy of LHC can be explained by activation of the transient receptor potential vanilloid subfamily member 1 (TRPV-1). ${ }^{23}$ LCH activates TRPV- 1 and thus causes calcium influx into the target cell. ${ }^{24}$ TRPV-1 in the skin is expressed in small to medium diameter sensoric neurons ( $\mathrm{C}$ - and $\mathrm{A}-\boldsymbol{\delta}$-fibers) as well as in other cells as keratinocytes, fibroblasts, endothelial cells, and mastocytes. ${ }^{25}$ Its physiological functionality is assumed to be connected with thermal sensory perception and neuro-immunological reaction pattern. The long-term analgesic and antipruritic effect can be explained by the inhibition of neurogenic inflammatory processes as well as mainly by the alterations in axonal integrity. ${ }^{26}$ Another hypothesis for the efficacy of
LCH concentrates on HSPs. ${ }^{27,28}$ The expression of HSPs is intensified under stress conditions (eg, heat), thus HSPs induce convolution of secondary structures of proteins in order to prevent denaturation. In cells infected with HSV-1 intensified expression of HSP70 and HSP72 could be detected even without heat stress. ${ }^{29}$ The range of induced HSPs under heat stress varies depending on cell type. ${ }^{30}$ For keratinocytes, HPS27 is considered to play a major role. ${ }^{31}$ Intensified expression of HSP27 inhibits the release of pro-inflammatory mediators by modulating nuclear factor kappa-light-chain-enhancer of activated B cells (NF- $\mathrm{\kappa B}$ ) signaling, ${ }^{32}$ which has immunomodulating effects. Specific investigations on HSV-1 infected keratinocytes under heat 
conditions have not been carried out so far. The relevance of HSP in terms of any antiviral effects of LCH is not based on adequate reasoning and very unlikely.

A direct thermal inactivation of HSV-1 could not yet be proven. ${ }^{33-35}$ An alternative hypothesis is based on the assumption of heat sensitive inhibition of the viral reproduction. However, data exists that contradicts this hypothesis showing that within the temperature range under review an induction of viral reproduction can be expected. ${ }^{36}$ Speculations about heat sensitive inhibition of DNAse activity ${ }^{37}$ or about heat sensitive inhibition of infectivity ${ }^{38}$ have been disproved. For an induction of an intensified synthesis of nitric oxide (NO), which, depending on concentration, can cause antiviral effects via oxidative mechanisms, ${ }^{39,40}$ the duration of application is far too short. ${ }^{21,41}$ It is known that there is a bi-phase vasogenic response: metabolic interactions via induction of inducible NO synthase can be expected at the earliest after approximately 10 minutes. ${ }^{22,42}$

Overall, the presented data clearly indicate that $\mathrm{LCH}$ reduces the prodromal symptoms pruritus and burning that are the main factors for worsening QoL. Possibly, the efficacy of LCH can be explained by the activation of TRPV-1 (similar to Capsaicin), ${ }^{43}$ which, in the medium term, inhibits the functionality of small to medium diameter sensoric neurons. Although direct impact on the replication of the virus cannot be ruled out completely, it could not be proven so far, either in vitro or in vivo.

\section{Acknowledgments}

This study was completely sponsored by Riemser Pharma $\mathrm{GmbH}$. The authors are very grateful to the staff of the pharmacies involved. We also acknowledge the excellent statistical analysis of Mr Julius Mungo and Mrs Anja Berensmeier.

\section{Disclosure}

$\mathrm{CM}$ was a former employee of Riemser Pharma $\mathrm{GmbH}$ while LCB and FV are currently employees. JW received lecturing fees, used to be co-operating partner in scientific projects and investigator in clinical studies sponsored by Riemser Arzneimittel AG and Riemser Pharma GmbH. The authors report no other conflicts of interest in this work.

\section{References}

1. Mettenleiter. Herpesviren. In: Doerr HWGW, editor. Medizinische Virologie. Stuttgart, New York: Thieme Verlag. 2010:653-665. German.

2. Sauerbrei A, Wutzler P. Herpes simplex and varicella-zoster virus infections during pregnancy: current concepts of prevention, diagnosis and therapy. Part 1: herpes simplex virus infections. Med Microbiol Immunol. 2007;196(2):89-94.
3. Hafezi W, Lorentzen EU, Eing BR, et al. Entry of herpes simplex virus type 1 (HSV-1) into the distal axons of trigeminal neurons favors the onset of nonproductive, silent infection. PLoS Pathog. 2012;8(5): e1002679.

4. Gupta R, Warren T, Wald A. Genital herpes. Lancet. 2007;370(9605): 2127-2137.

5. Haarr L, Skulstad S. The herpes simplex virus type 1 particle: structure and molecular functions. Review article. APMIS. 1994;102(5):321-346.

6. Scott DA, Coulter WA, Lamey PJ. Oral shedding of herpes simplex virus type 1: a review. J Oral Pathol Med. 1997;26(10):441-447.

7. Looker KJ, Garnett GP. A systematic review of the epidemiology and interaction of herpes simplex virus types 1 and 2. Sex Transm Infect. 2005;81(2):103-107.

8. Stuart-Harris C. The epidemiology and clinical presentation of herpes virus infections. J Antimicrob Chemother. 1983;12 Suppl B:1-8.

9. Arduino PG, Porter SR. Oral and perioral herpes simplex virus type 1 (HSV-1) infection: review of its management. Oral Dis. 2006; 12(3):254-270.

10. Cunningham A, Griffiths P, Leone P, et al. Current management and recommendations for access to antiviral therapy of herpes labialis. J Clin Virol. 2012;53(1):6-11.

11. Girard M. Safety of acyclovir in general practice: a review of the literature. Pharmacoepidemiol Drug Saf. 1996;5(5):325-332.

12. Kabra NS, Thabane L. Acyclovir prophylaxis to prevent herpes simplex virus recurrence at delivery: a systematic review. Obstet Gynecol. 2004;103(5 Pt 1):1004; author reply 1004-1004; author reply 1005.

13. Herpotherm [package insert]. Greifswald, Germany: Riemser Pharma GmbH; 2012.

14. Dréno B, Malkin JE, Saiag P, Batuji-Garin S. Patients' profile, burden of disease and quality of life in recurrent herpes labialis: a survey conducted in USA and France. J Eur Acad Dermatol Venereol. 2012;26(11): $1458-1460$

15. Müller C, Großjohann B, Fischer L. The use of concentrated heat after insect bites/stings as an alternative to reduce swelling, pain, and pruritus: an open cohort-study at German beaches and bathing-lakes. Clin Cosmet Investig Dermatol. 2011;4:191-196.

16. Henriques FC, Moritz AR. Studies of Thermal Injury: I. The Conduction of Heat to and through Skin and the Temperatures Attained Therein. A Theoretical and an Experimental Investigation. Am J Pathol. 1947;23(4):530-549.

17. Moritz AR, Henriques FC. Studies of Thermal Injury: II. The Relative Importance of Time and Surface Temperature in the Causation of Cutaneous Burns. Am J Pathol. 1947;23(5):695-720.

18. McGee MP, Morykwas MJ, Argenta LC. The local pathology of interstitial edema: surface tension increases hydration potential in heat-damaged skin. Wound Repair Regen. 2011;19(3):358-367.

19. Tanaka M. Local skin thermal responses to heat radiation. Sangyo Igaku. 1985;27(2):90-96.

20. Wingo JE, Low DA, Keller DM, Brothers RM, Shibasaki M, Crandall CG. Skin blood flow and local temperature independently modify sweat rate during passive heat stress in humans. J Appl Physiol (1985). 2010;109(5):1301-1306.

21. Pearson J, Lucas RA, Crandall CG. Elevated local skin temperature impairs cutaneous vasoconstrictor responses to a simulated haemorrhagic challenge while heat stressed. Exp Physiol. 2013;98(2):444-450.

22. Widmer RJ, Laurinec JE, Young MF, Mohiuddin MW, Laine GA, Quick CM. The origin of the biphasic flow response to local heat in skin. Microcirculation. 2008;15(4):349-357.

23. Hagenacker T, Ledwig D, Büsselberg D. Feedback mechanisms in the regulation of intracellular calcium $([\mathrm{Ca} 2+] \mathrm{i})$ in the peripheral nociceptive system: role of TRPV-1 and pain related receptors. Cell Calcium. 2008;43(3):215-227.

24. Knotkova H, Pappagallo M, Szallasi A. Capsaicin (TRPV1 Agonist) therapy for pain relief: farewell or revival? Clin J Pain. 2008;24(2): $142-154$.

25. Lee YM, Kang SM, Chung JH. The role of TRPV1 channel in aged human skin. J Dermatol Sci. 2012;65(2):81-85. 
26. Kueper T, Krohn M, Haustedt LO, Hatt H, Schmaus G, Vielhaber G. Inhibition of TRPV1 for the treatment of sensitive skin. Exp Dermatol. 2010;19(11):980-986.

27. Moriya A, Yoshiki A, Kita M, Fushiki S, Imanishi J. Heat shockinduced reactivation of herpes simplex virus type 1 in latently infected mouse trigeminal ganglion cells in dissociated culture. Arch Virol. 1994;135(3-4):419-425.

28. Mathew SS, Della Selva MP, Burch AD. Modification and reorganization of the cytoprotective cellular chaperone Hsp27 during herpes simplex virus type 1 infection. J Virol. 2009;83(18):9304-9312.

29. Kobayashi K, Ohgitani E, Tanaka Y, Kita M, Imanishi J. Herpes simplex virus-induced expression of $70 \mathrm{kDa}$ heat shock protein (HSP70) requires early protein synthesis but not viral DNA replication. Microbiol Immunol. 1994;38(4):321-325.

30. Lehner T. The role of heat shock protein, microbial and autoimmune agents in the aetiology of Behçet's disease. Int Rev Immunol. 1997; 14(1):21-32.

31. Bektas M, Rubenstein DS. What's in a name?: Heat shock protein 27 and keratinocyte differentiation. J Invest Dermatol. 2010;130(1):10-12.

32. Lu SY, Chang KW, Liu CJ, et al. Ripe areca nut extract induces G1 phase arrests and senescence-associated phenotypes in normal human oral keratinocyte. Carcinogenesis. 2006;27(6):1273-1284.

33. Plummer G, Lewis B. Thermoinactivation of herpes simplex virus and cytomegalovirus. J Bacteriol. 1965;89:671-674.

34. Ruyechan WT, Chytil A, Fisher CM. In vitro characterization of a thermolabile herpes simplex virus DNA-binding protein. $J$ Virol. 1986;59(1):31-36.
35. Hunsperger EA, Wilcox CL. Capsaicin-induced reactivation of latent herpes simplex virus type 1 in sensory neurons in culture. J Gen Virol. 2003;84(Pt 5):1071-1078.

36. Danaher RJ, Jacob RJ, Chorak MD, Freeman CS, Miller CS. Heat stress activates production of herpes simplex virus type 1 from quiescently infected neurally differentiated PC12 cells. J Neurovirol. 1999;5(4): 374-383.

37. Morrison JM, Keir HM. Heat-sensitive deoxyribonuclease activity in cells infected with herpes simplex virus. Biochem J. 1966;98(3): 37C-39C.

38. Fenyves A, Strupp L. Heat-resistant infectivity of herpes simplex virus revealed by viral transfection. Intervirology. 1982;17(4):228-239.

39. Mannick JB. The antiviral role of nitric oxide. Res Immunol. 1995; 146(9):693-697.

40. Powell KL, Baylis SA. The antiviral effects of nitric oxide. Trends Microbiol. 1995;3(3):81-82.

41. Kellogg DL, Zhao JL, Wu Y. Roles of nitric oxide synthase isoforms in cutaneous vasodilation induced by local warming of the skin and whole body heat stress in humans. J Appl Physiol (1985). 2009;107(5): 1438-1444.

42. Petrofsky J, Bains G, Prowse M, et al. Does skin moisture influence the blood flow response to local heat? A re-evaluation of the Pennes model. J Med Eng Technol. 2009;33(7):532-537.

43. Gooding SM, Canter PH, Coelho HF, Boddy K, Ernst E. Systematic review of topical capsaicin in the treatment of pruritus. Int J Dermatol. 2010;49(8):858-865.
Clinical, Cosmetic and Investigational Dermatology

\section{Publish your work in this journal}

Clinical, Cosmetic and Investigational Dermatology is an international, peer-reviewed, open access, online journal that focuses on the latest clinical and experimental research in all aspects of skin disease and cosmetic interventions. All areas of dermatology will be covered; contributions will be welcomed from all clinicians and

\section{Dovepress}

basic science researchers globally. This journal is indexed on CAS The manuscript management system is completely online and includes a very quick and fair peer-review system, which is all easy to use. Visit http://www.dovepress.com/testimonials.php to read real quotes from published authors. 